\title{
INVESTIGAÇÃO SOBRE A FORMAÇÃO DO CLERO CATÓLICO NUM SEMINÁRIO TEOLÓGICO'
}

Sílvio José Benelli*

\begin{abstract}
RESUMO. Neste artigo procuramos fazer uma análise psicossocial de um seminário teológico católico onde vivem 50 seminaristas em regime de internato, na etapa final de preparação para o sacerdócio, os quais, uma vez ordenados, passarão a ocupar posições de relevância, que consistem na coordenação de comunidades paroquiais amplas. Utilizando o instrumental teórico da análise institucional, procuramos mapear os operadores institucionais subjetivadores do dispositivo pedagógico seminário. Apresentamos dados relativos à observação participante realizada no campo de investigação. Detectamos que o seminário, além dos operadores presentes no discurso oficial institucional, implementa na prática cotidiana outros procedimentos, que podem ser designados como totalitários e disciplinares, produzindo um padre de perfil clericalizado.
\end{abstract}

Palavras-chave: psicologia social, pedagogia, educação do clero.

\section{INVESTIGATING THE ECCLESIASTICAL CATHOLIC FORMATION AT THE THEOLOGICAL CATHOLIC SEMINARY}

\begin{abstract}
We sought to execute a psychosocial analysis of a Theological Catholic Seminary where live 50 seminarians in boarding system, at the final stage of formation to priesthood; once ordained, they will be settled in relevant positions that comprise in the coordination of large parish communities. Applying a theoretical tool of institutional analysis, we mapped institutional subjectivityoperators from the pedagogical device in the Seminary. We show data related to participative observation obtained in research field. Besides the operators present in the official and institutional discourse, we found out that the Seminary contrives in daily practice other procedures, which may be designated as totalitarian and disciplinary, producing a priest with clerical profile.
\end{abstract}

Key words: Social Psychology, pedagogy, clerical education.

\section{INVESTIGACIÓN SOBRE LA FORMACIÓN DEL CLERO CATÓLICO EN UN SEMINARIO DE TEOLOGOS}

\begin{abstract}
RESUMEN. En este artículo pretendemos hacer un analisis psicosocial de un seminário católico de teologia donde viven 50 seminaristas en régimen de internado, en la etapa final de su preparación para el sacerdocio, y que, una vez ordenados, pasarán a ocupar posiciones relevantes que consisten en la coordinación de amplias comunidades parroquiales. Utilizando el instrumental teórico del analisis institucional buscamos mapear los operadores institucionales subjetivadores del dispositivo pedagógico seminario. Presentamos datos relativos a la observación participante realizada en el campo de investigación. Detectamos que el seminário, más allá de los operadores presentes en el discurso institucional, implementa, en la práctica cotidiana, otros procedimientos que puedan ser designados como totalitários y disciplinares, produzindo un sacerdote de perfil clericalizado.
\end{abstract}

Palabras-clave: Sicología social, pedagogia, educacion del clero.

\section{O SEMINÁRIO CATÓLICO COMO INSTITUIÇÃO DE FORMAÇÃO DO CLERO}

A Igreja Católica prepara os membros do clero no estabelecimento seminário. Os candidatos ao sacerdócio passam ao redor de oito anos percorrendo várias etapas em diversas instituições de formação: seminário menor, propedêutico, seminário filosófico e teológico. Esses anos de vida institucionalizada

\footnotetext{
1 Apoio: Capes.

* Psicólogo. Doutor em Psicologia Social.
} 
produzem efeitos na subjetividade dos seminaristas e configuram um tema de estudo apropriado e relevante em si mesmo. Há trabalhos realizados por padres formadores que não pertencem ao campo acadêmico propriamente, mas são produzidos pelas necessidades da própria instituição eclesial (Centini \& Manenti, 1988; João Paulo II, 1992; Marmilicz, 2003; Mézerville, 2000; Pereira, 2004). Não encontramos relatos na literatura disponível que desenvolvam abordagens do seminário católico desde uma perspectiva institucional como a que estamos empreendendo, a qual, por ser original e inusitada, revela aspectos até então insuspeitados da formação do clero, podendo causar certa estranheza. É raro conseguir autorização do clero para estudar a vida institucional do seminário.

Como é que a instituição seminário católico prepara os futuros padres? Como ela funciona e o que produz? Que procedimentos utiliza no processo formativo do clero? Nosso objetivo é problematizar as práticas formativas eclesiásticas católicas, tais como elas se apresentam nos modos institucionais de funcionamento do seminário católico e no registro do saber eclesiástico, enquanto produtoras de uma possível subjetividade eclesiástica (futuros padres). Pouco se sabe, no meio acadêmico, a respeito dessa realidade. Um caminho para lidar com essa dificuldade é uma produção científica que ofereça um maior conhecimento da subjetividade que se produz e se desenvolve nesse ambiente social e institucional específico. $\mathrm{O}$ estabelecimento seminário costuma receber um número razoável de indivíduos todos os anos e trabalha com eles, formando-os para ocupar um lugar preeminente na liderança de setores relevantes da população, orientando-os e exercendo grande influência sobre eles.

O seminário teológico é uma etapa avançada do processo formativo do candidato ao sacerdócio, provavelmente dotado de especificidades que desconhecemos. Ali o seminarista vive em comunidade e está diante da ordenação sacerdotal de modo concreto e mais próximo. Recebe formação teológica, doutrinal, espiritual e pastoral específica para o futuro exercício do ministério presbiteral (Conferência Nacional dos Bispos do Brasil, 1995; Igreja Católica, 1982; 1985) e vai percorrendo os diversos graus do sacramento da ordem: é admitido oficialmente como seminarista por sua diocese, recebe os ministérios de acólito e leitor; mais tarde é ordenado diácono, quando promete publicamente viver o celibato, e finalmente o processo formativo culmina com a ordenação sacerdotal. Entendemos que para estudar como estão sendo formados os seminaristas católicos, que futuramente serão padres, seria útil uma abordagem institucional através da qual pudéssemos problematizar as práticas formativas (práticas discursivas, práticas de poder e tecnologias de si) que são implementadas num seminário teológico, tomando essa instituição como dispositivo de produção de subjetividade. Estamos tecendo uma grade de análise composta pela análise institucional na perspectiva da produção de subjetividade.

\section{A ANÁLISE INSTITUCIONAL COMO INSTRUMENTO DE INVESTIGAÇÃO}

Para estudarmos a multifacetada realidade que é a formação sacerdotal e a instituição seminário católico onde ela se processa, necessitamos de uma abordagem também complexa. Nossa perspectiva pautou-se pela análise institucional (Baremblitt, 1998; Barus-Michel, 2004; Costa-Rosa, 2000; Foucault, 1999; Goffman, 1987; Lourau, 1996), que nos permitem realizar uma pesquisa transversal, transitando por diferentes campos de saberes e práticas sociais: história da Igreja, teologia católica, eclesiologia, psicologia social dialética, pensamento institucionalista e também foucaultiano, buscando cartografar nosso objeto. A análise institucional é uma prática que se insere no Movimento Institucionalista (Baremblitt, 1998). O objetivo de conjunto dessas tendências é propiciar e apoiar processos de auto-análise e autogestão dos coletivos sociais: comunidades, grupos, instituições, etc. Utilizamos alguns recursos teórico-técnicos da Análise Institucional. O institucionalismo afirma que a sociedade é um tecido de instituições. As instituições, segundo o grau de formalização que adotem, podem ser leis, normas ou regularidades de comportamento, por exemplo, a linguagem, as relações de parentesco, a educação, a religião, etc. As instituições se materializam em dispositivos concretos, as organizações, que por sua vez se compõem de unidades menores, nomeadas de estabelecimentos. Os estabelecimentos costumam incluir dispositivos técnicos: as instalações materiais, maquinaria, arquivos, aparelhos. Esse conjunto de elementos recebe o nome de equipamentos. Todos esses elementos - instituição, organização, estabelecimento, equipamento - adquirem dinamismo através dos agentes (atores institucionais), os sujeitos que são os suportes e protagonistas da atividade coletiva microfísica responsável pela substância da instituição. Os atores institucionais protagonizam práticas sociais que podem ser verbais, não-verbais, discursivas, teóricas ou técnicas. Para entender e analisar uma instituição, devemos ter em mente que os instituídos, 
os organizantes/organizados que constituem a rede social, não atuam separadamente, eles se interpenetram em vários níveis. Atravessamento é o nome que damos à interpenetração no nível reprodutivo, conservador. Transversalidade se chama o movimento de interpenetração no nível do instituinte, do criativo, do novo.

A leitura de Goffman (1987) a partir das análises de Foucault (1999) pode nos proporcionar um enriquecimento fecundo na compreensão dos processos de produção de subjetividade na sociedade contemporânea e, de modo específico, no contexto das instituições totais, que estão longe de ter desaparecido. Ambos nos parecem referenciais adequados para realizar análises institucionais (Benelli, 2004; 2006a). Costa-Rosa (2000) também produziu uma interessante grade de análise lógico-histórica de inspiração marxista dialética, mapeando paradigmas contraditórios no campo da saúde mental pública e articulando os temas da instituição e da produção de subjetividade. Ele propõe quatro parâmetros mínimos como definidores de determinado paradigma de produção na saúde mental: a) concepções de "objeto" e dos "meios" de ação; b) concepções das formas de organização do dispositivo institucional; c) modos da inter-relação instituição, clientela, população e território e população-instituição; d) concepções dos efeitos terapêuticos e seus desdobramentos éticos. Tal instrumental tem se mostrado útil também para análises institucionais em outros campos, como os da psicologia, da educação e da religião católica (Benelli, 2006a; Benelli, 2006b; Benelli \& Costa-Rosa, 2006). Apesar da amplitude do nosso enfoque, neste artigo privilegiamos o instrumental analítico genealógico como recorte estratégico para a compreensão da estrutura e dinâmica do seminário investigado.

\section{GENEALOGIA DE UM REFORMATÓRIO COMO CASO SINGULAR}

Foucault (1999) analisou exemplarmente um estabelecimento denominado "colônia de Mettray", que funcionava como um reformatório e havia sido construído a partir de uma nova política punitiva do corpo. Sua forma disciplinar é intensa e seu modelo concentra todas as tecnologias coercitivas do comportamento: ela tem aspectos do claustro monástico, da prisão, do colégio e do regimento militar. Os rapazes ali confinados são divididos em pequenos grupos fortemente hierarquizados, de acordo com cinco modelos de referência: a) esquema da família (grupo composto por "irmãos" e "pais"); b) esquema do exército (grupo comandado por um chefe, dividido em seções com subchefes; número de matrícula, aprendizado de exercícios militares básicos; revistas de limpeza do corpo e das roupas, chamada realizada três vezes ao dia); c) esquema da oficina (chefes e contramestres asseguram o aprendizado do trabalho); d) esquema escolar (professor e monitores ministram aulas); e) esquema judiciário (o microtribunal penal realiza todos os dias uma "distribuição de justiça", cuja penalidade principal é a solitária, em cujas paredes se lê em letras pretas: "Deus o vê"). Essa superposição de modelos diferentes permite determinar a função de "adestramento" no que ela tem de específico: a equipe dirigente tem a função de "técnicos do comportamento, engenheiros da conduta, ortopedistas da individualidade" (Foucault, 1999, p. 244). Ela tem que fabricar ao mesmo tempo corpos dóceis e capazes de trabalhar, utilizando uma observação permanente que avalia continuamente o comportamento cotidiano dos detentos. Trata-se de um saber organizado como instrumento de apreciação perpétua. A modelagem do corpo dá lugar a um conhecimento do indivíduo, o aprendizado das técnicas induz a modos de comportamento e a aquisição de aptidões se mistura com a fixação de relações de poder; formando-se bons agricultores, vigorosos e hábeis. Nesse mesmo trabalho, desde que tecnicamente controlado, fabricam-se indivíduos submissos e constitui-se sobre eles um saber em que se pode confiar. Um duplo efeito dessa técnica disciplinar é exercido sobre os corpos: uma "alma" a conhecer e uma sujeição a manter.

Nessa operação de adestramento, a Mettray é exemplar e específica. Ela se aproxima de outras formas de controle sobre as quais se apóia: medicina, educação escolar, direção espiritual religiosa; mas não se confunde com elas nem com administração propriamente dita. A equipe dirigente vivia permanentemente com os rapazes reclusos, constituindo no meio deles uma rede de observação perpétua. Tal equipe era formada numa escola especializada na qual era submetida aos mesmos aprendizados e coerções que seriam utilizados mais tarde com os detentos. Os membros da equipe dirigente eram submetidos à mesma disciplina que deveriam, como educadores, impor aos jovens. Aprendiam na prática a técnica, "a arte das relações de poder" (Foucault, 1999, p. 245), mais do que teorias. O "penitenciário", a "lógica totalitária", é uma técnica que se aprende e se transmite e que obedece a normas gerais. A técnica disciplinar tornou-se um saber e fez escola. É a partir desse limiar diferencial que surge, nessa época, a psicologia científica, aparecendo os 
profissionais da disciplina, da normalidade e da sujeição. Mettray está no limite da penalidade estrita. Outras instituições, bem além do direito penal, construíram o "arquipélago carcerário" (Foucault, 1999, p. 246): colônias agrícolas para adultos e crianças pobres, abandonadas e vadias; refúgios para tirar moças e meninas da prostituição; colônias penitenciárias industriais; orfanatos para crianças abandonadas ou indigentes; estabelecimentos para aprendizes; fábricas-conventos, etc. Houve um alargamento dos círculos carcerários, e nessas instituições a prisão foi se diluindo lentamente, até desaparecer por completo. A tecnologia disciplinar e panóptica implementada em Mettray colonizou diversas instituições sociais criadas com objetivos educacionais, prisionais, médicos e assistenciais. Trabalhamos com a hipótese de que ela está presente e atuante também no estabelecimento seminário e na formação do clero, como buscamos demonstrar.

Foucault (1999) desenvolveu uma análise histórica do desenvolvimento das práticas punitivas e disciplinares que nos parece muito adequada para analisarmos a atual formação institucional do clero católico. De uma perspectiva institucional genealógica, a formação social seminário católico parece se organizar a partir dos operadores apresentados por Foucault, que seriam parte do não-dito e do não-sabido das funções institucionais tradicionais. Enquanto equipamento, o seminário teológico emprega práticas discursivas e práticas de poder, e implementa práticas de si que têm como efeito a produção institucional de sujeitos, de atores sociais, de padres católicos. Estudando o plano dos saberes teológicos e espirituais, a dimensão das práticas psicopedagógicas cotidianas através da observação participante e de entrevistas semidirigidas, pudemos captar os diversos processos através dos quais se produz subjetividade no seminário teológico católico.

\section{Sujeitos da pesquisa}

Os sujeitos dessa pesquisa incluem um estabelecimento denominado Seminário Teológico Diocesano Católico, localizado no interior do Estado de São Paulo, e seus diversos atores institucionais: seminaristas estudantes de teologia - cujas idades variam entre 22 e 40 anos -; padres formadores: reitor, diretor de estudos, diretor espiritual - cujas idades variam entre $48 \mathrm{e}$ 65 anos -, além de professores, técnicos administrativos e demais funcionários. $\mathrm{O}$ número de seminaristas em formação varia conforme o ano, mas normalmente há entre 40 e 60 formandos no seminário. A única condição que os responsáveis pelo seminário teológico colocaram para a realização da pesquisa foi o sigilo quanto à sua identificação, portanto não podemos fazê-lo por razões éticas. O seminário teológico é constituído por uma grande propriedade e diversos edifícios, que abrigam salas de aula, dormitórios, refeitório, capela, igreja, biblioteca, ambientes e espaços de convivência, tais como pátios e jardins. Ali se realiza a preparação teológica dos candidatos ao sacerdócio, que cursam o bacharelado em teologia, com quatro anos de duração. Além das atividades acadêmicas, outras dimensões específicas do processo formativo sacerdotal são implementadas no estabelecimento: vida comunitária, formação humanoafetiva, dimensão vocacional e espiritual e, ainda, atividades pastorais (Conferência Nacional dos Bispos do Brasil, 1995). Para conhecer o seminário teológico em seu funcionamento cotidiano e coletar dados para nossa análise institucional, utilizamos a estratégia da observação participante. Numa fase posterior dessa pesquisa também utilizamos a técnica da entrevista semidirigida (Blerger, 1980; Thompson, 1992), para obter informações dos atores institucionais quanto à vida que levam no estabelecimento. Neste artigo apresentaremos apenas resultados parciais, com base em nossas observações do campo de investigação. O resultado da análise das entrevistas será objeto de um artigo futuro.

\section{Observação participante}

Para realizar esta pesquisa utilizamos a técnica da observação participante, qualitativa, rigorosa, sistemática e vivencial. Participação não implicou um delineamento conjunto, pois não havia demanda de análise por parte da instituição seminário, embora houvesse bastante sofrimento ali. A técnica da observação participante (Alves-Mazzotti,1999) foi utilizada e reorientada para manter-se adequada e sensível às características da situação. Entendemos a pesquisa como prática investigativa e participação como valorização e uso das perspectivas vivenciadas pelos sujeitos na vida e em ambientes cotidianos. A técnica da observação participante envolveu três fases: (1) aproximação da instituição e estabelecimento de vínculos com seus membros; (2) realização da observação no contexto dos sujeitos para a coleta de dados; e (3) registro posterior dos fenômenos, comportamentos, ações, diálogos e acontecimentos observados. Acompanhamos a vida institucional do seminário teológico durante 03 três anos consecutivos.

\section{RESULTADOS DAS OBSERVAÇÕES DE CAMPO}

Elaboramos um exaustivo relatório sobre as visitas de observação participante, do qual aqui somente apresentaremos alguns elementos, a partir dos 
quais esboçaremos algumas análises preliminares. As expressões de caráter coloquial que aparecem entre aspas no texto a seguir foram emitidas pelos atores institucionais durante a investigação, por isso foram mantidas dessa forma. Observamos que já no primeiro ano do curso teológico o seminarista se depara com a questão da ordenação sacerdotal, com tudo o que ela implica: de um sonho distante que era no seminário menor ou no filosófico, torna-se uma realidade próxima e provável: "faltam apenas três anos agora", podendo então surgir novas angústias: "Será que vou dar conta? Será que vou estar preparado?" A dimensão acadêmica continua num marcante processo desmitologizante e desmistificador: "nossa fé ingênua treme e vacila diante dos estudos teológicos". A convivência é considerada mais tranqüila e agradável do que era no seminário filosófico: "é cada um por si e ninguém cuida da vida do outro"; o clima da casa é menos tenso, inclusive porque o espaço físico é maior, mais ajardinado, e o número de seminaristas é bem menor no seminário teológico do que no filosófico. É possível que o fato de ter conseguido chegar à etapa teológica da formação também dê mais segurança para os candidatos ao sacerdócio. Foi preciso superar com sucesso muitos obstáculos e dificuldades no percurso para, finalmente, chegar próximo ao final da formação.

Aparentemente, haveria grandes equívocos do estabelecimento de formação quanto aos interesses, necessidades e possibilidades da clientela composta pelos seminaristas teólogos. O seminarista já é licenciado em Filosofia, já é um jovem-adulto qualificado, inclusive desejoso e sedento de produzir, ávido por uma existência desafiadora, dinâmica, ativa, produtiva; mas a lógica totalitária que predomina no contexto institucional, com sua dinâmica niveladora e uniformizante, tende a apagar, suspender e anular distinções etárias, profissionais e pessoais (Goffman, 1987). Ela trata de modo igual os desiguais em suas necessidades e interesses. Não parece haver muitas brechas para projetos ou trajetórias mais personalizados. O jovem teólogo, tal como o filósofo, também ainda não é, não pode, não faz, não produz, apenas estuda. Somente o padre é, faz, pode, produz. O seminarista só poderá agir com autonomia quando for padre. Há um interessante "processo de resignação" ao longo da formação sacerdotal, pois a identidade clerical oferecida pela instituição não corresponde completamente aos anseios dos seminaristas teólogos, ela apresenta um caráter burocrático e disciplinar mais do que místico ou espiritual. Diante das pressões institucionais, é comum o seminarista desistir de "dar murro em ponta de faca" e aceitar o que lhe é imposto, esperando pela redenção da ordenação presbiteral, que vai lhe restituir a liberdade e a autonomia.

Os seminaristas teólogos, em sua maioria, mostram-se como indivíduos mais práticos, ativos, voltados para a atividade muito mais do que para o exercício intelectual teológico. Muitos sentem que o curso não é interessante, atraente e desafiador. Haveria uma multiplicação opressiva de disciplinas e de trabalhos escolares. Criticam o corpo docente como sendo fraco e as aulas como pouco estimulantes. Geralmente a expectativa do seminarista teólogo ao iniciar o curso é grande; em seguida ele parece ir desanimando com a dimensão acadêmica de "cunho pastoral" do curso teológico. A pastoral seria o eixo integrador do curso teológico (Conferência Nacional dos Bispos do Brasil, 1995), mas isso permanece mais no plano teórico do que no prático. Talvez a proposta curricular seja problemática ou a metodologia subestime a capacidade do aluno, tratando de assuntos pouco interessantes ou tratando os temas de modo simplista e "catequético", isto é, no nível iniciante. Muitos comentam que estudar teologia é aprender doutrina e dogmas, que devem ser recebidos e aceitos sem discussões ou polêmicas, para o seminarista não ser visto e "tachado" pelos demais como "herege" ou "ateu", o que poderia pôr em risco a permanência do indivíduo no processo formativo e, no limite, inviabilizar a tão sonhada e almejada ordenação sacerdotal. Faltaria articulação entre a formação filosófica - que não estimula as opções de fé e o engajamento pastoral - e a formação teológica, evidenciando a necessidade de um trabalho de síntese. Os alunos apresentam dificuldades na produção de trabalhos escritos, tendem a encarar o plano intelectual como algo estanque, pois na prática, "a teoria não teria nada a ver com o dia-a-dia”. Isso gera uma resistência aos estudos, que são sofridos e arrastados. O tempo para os estudos pessoais é reduzido, "porque o horário no seminário é todo picado". A semana do seminarista termina na sexta-feira ao meio-dia, quando ele parte para as atividades pastorais obrigatórias de fim de semana, retornando cansado no domingo à noite. Apenas na segunda-feira à noite - depois das aulas matinais e de uma tarde de trabalhos domésticos e de jardinagem - é que ele reencontrará horário para o estudo pessoal. Embora morar no seminário sem trabalhar seja exigido como condição para que o seminarista tenha todo o tempo para estudar, não é isso que realmente acontece. Há muitas atividades que tomam tempo de estudo do seminarista: reuniões, tempos de oração, tarefas de faxina e limpeza da casa, reuniões de turma, de diocese, etc. Temos constatado 
também que o seminarista teólogo médio não suporta estudar o dia inteiro cansando-se e aborrecendo-se com o trabalho intelectual, que de fato não deixa de ser uma atividade estafante. A rotina e o tédio parecem dificultar ainda mais os estudos. Parece que a facilidade se transforma em agente promotor de dificuldades e a formação gratuita no contexto de um estabelecimento totalitário torna-se, assim, ineficaz. Teoricamente, o seminarista tem condições ideais para estudar: não precisa se preocupar com trabalho para sua sobrevivência, tem os estudos, casa, comida e roupa lavada, tudo pronto, tudo pago; mas o gosto pela vida intelectual não parece predominante entre os teólogos, candidatos ao clero diocesano. Notamos, desde o seminário filosófico, que as habilidades artísticas, tais como capacidade de animar e falar com massas, tocar violão, cantar, produzir decoração e cerimônias litúrgicas visualmente atraentes, de expressão corporal e teatral, são mais importantes para os seminaristas do que a aptidão para o trabalho propriamente intelectual e acadêmico. A prática pedagógica desenvolvida não parece eficiente, pois não atenta para as reais necessidades e interesses dos seminaristas.

É provável que se os seminaristas tivessem um trabalho profissional estimulante e desafiador, no qual se sentissem úteis, empolgados e produtivos, recebendo remuneração para pagar os custos do processo formativo, estudariam mais, aproveitariam mais o que lhes é oferecido na formação. Parece que, atualmente, os seminaristas têm grande dificuldade em valorizar adequadamente aquilo que é totalmente gratuito. $\mathrm{O}$ valioso parece ser aquilo que custa, que é caro, aquilo que se paga com esforço. Mas observamos que a "total gratuidade" do processo formativo sacerdotal realizado no estabelecimento seminário "custa caro" para os candidatos, pois eles devem permanecer confinados por longos anos em estruturas, ambientes e relações sociais que poderiam ser considerados quase medievais.

Supomos que a instituição seminário católico, agência privilegiada de formação do clero, com seus problemas típicos, é altamente sensível às configurações eclesiológicas divergentes e contraditórias do cenário eclesial global (Benelli, 2006a; 2006b). Num ambiente onde seus interesses, necessidades e possibilidades pessoais e coletivas são tacitamente reinterpretadas pela lógica totalitária específica do seminário clássico tridentino, uma criação do Paradigma Romano (Libanio, 1984; Benelli, 2006b) no contexto eclesial global, notamos o intenso sofrimento que se produz no ambiente institucional do seminário através do "narcisismo das pequenas diferenças". Há uma amplificação e intensificação exagerada de pequenos incidentes da vida cotidiana que em outras circunstâncias passariam despercebidos. Quando o que é relevante para a produção de uma existência significativa e produtiva fica suspenso, interditado, como acontece nas instituições totais em geral (Goffman, 1987), abre-se largo espaço para o império inútil e desgastante das "picuinhas" e futricas ordinárias do cotidiano.

\section{Operadores institucionais disciplinares e clericalizadores do seminário}

A formação do clero seria um domínio ainda flutuante, constituindo um campo de noções conexas que reconhecemos como pertinentes aos saberes pedagógicos, psicológicos e teológicos. No claustro totalitário o seminarista é privado da liberdade e autonomia relativas que desfrutava antes do seu ingresso no estabelecimento, ficando submetido aos superiores imediatos: bispos, padres formadores, professores e aos colegas que ocupam cargos de confiança. Ele deve aprender a obediência. Não tem renda nem salário e fica dependente da diocese, do padre da pastoral, de "madrinhas" que financiem suas necessidades pessoais como material escolar, saúde, vestuário, higiene pessoal, etc. Deve aprender a pobreza e simplicidade pessoal, embora viva numa casa que tem um padrão de classe média alta e curse uma faculdade particular sem trabalhar para pagá-la. Nestes longos anos de tutela informal e cobertura incompleta de suas necessidades, o seminarista aprende a dependência e a submissão. Sofre um processo de infantilização no qual regride para uma adolescência e moratória social prolongadas: não pode ter trabalho remunerado, não pode fazer sexo, não pode decidir por si mesmo nem as pequenas coisas do cotidiano, tem que aprender a pedir permissão e autorização dos superiores para sair do estabelecimento, dar satisfações de onde vai, como vai, por que e com quem vai, onde passa suas férias, etc.

A vida comunitária é uma dimensão formativa oferecida pelo seminário como elemento operador da formação sacerdotal. Viver no seminário como membro da comunidade formativa constituída por seminaristas e padres formadores exige um enclaustramento, uma relativa privação da liberdade do seminarista. Não podemos falar de "encarceramento" nem "detenção", pois o jovem ingressa no seminário por iniciativa pessoal e também pode deixá-lo quando o desejar; mas o enclaustramento no estabelecimento seminário possui um "suplemento corretivo", um excesso disciplinar 
que visa à modificação e transformação dos seminaristas. Nossa hipótese é que o enclaustramento é uma exigência implícita do processo de "clericalização" que o funcionamento institucional produz e gerencia. Ingressar no seminário implica abrir mão da própria liberdade. Essa privação da liberdade ainda submete o seminarista à autoridade da equipe dirigente (padres formadores): ele deve obedecer às "normas da casa" prescritas no regimento interno, pedir permissão aos superiores para realizar diversas atividades e acatar docilmente as correções que lhe fizerem. A privação da liberdade no claustro do seminário inclui uma cláusula específica no que podemos denominar de "contrato informal de formação" entre padres formadores e jovens vocacionados ingressantes no seminário: regra de submissão obediente aos padres formadores, os "superiores". Os seminaristas não emitem o voto de obediência religiosa, mas devem observá-lo rigorosamente na prática cotidiana. Estão mais obrigados à obediência (mesmo sem emiti-lo oficialmente) do que os padres formadores (que se comportam como adultos autônomos, livres, capazes de tomar decisões, pessoas trabalhadoras e assalariadas, que vêm e vão sem problemas e sem necessidade de dar satisfações, etc.). Tais técnicas corretivas fazem parte da estrutura institucional típica do seminário; não são acessórias nem acidentais, são elementos do cotidiano, das práticas não-discursivas. $O$ seminarista é, assim, treinado numa atividade inútil e resignada, desenvolvendo hábitos de uma sociabilidade submissa. Quando ele estiver bem disciplinado, tendo interiorizado valores, hábitos, discursos e práticas oficiais, depois de anos de "educação total" no claustro do seminário, ao ser ordenado como membro da hierarquia clerical, recuperará sua condição de adulto livre, autônomo e responsável. Além do contato permanente com os padres formadores, o seminarista tem uma obrigatória continuidade de contato com seus pares, fato que costuma produzir também efeitos adversos no microcosmo institucional (Benelli, 2006a; 2006b; Goffman, 1987). O enclaustramento como operador da formação sacerdotal produz uma recodificação da existência do jovem transformado em seminarista: ele é isolado do mundo exterior e inserido no grupo dos seminaristas em formação. Ali estará sujeito a todas as vicissitudes de um grupo monossexuado em regime de internato: cumplicidade, associações misteriosas, solidariedade, contágio moral, ajustamentos primários e secundários, conforme Goffman (1987) já havia detectado.
O seminário se revela então como um "aparelho disciplinar exaustivo" (Foucault, 1999, p. 198). Ele toma a seu cargo todos os aspectos do indivíduo: sua sobrevivência física, sua aptidão para o trabalho, seu comportamento cotidiano, sua atitude moral, suas disposições, sua sexualidade. O seminário pode ser considerado um estabelecimento "onidisciplinar", "sem exterior nem lacuna; não se interrompe, a não ser depois de terminada totalmente sua tarefa; sua ação sobre o indivíduo deve ser ininterrupta: disciplina incessante" (Foucault, 1999, p. 198-199). No estabelecimento a equipe dirigente possui um poder quase total sobre os seminaristas: há mecanismos internos próprios de repressão, castigo, premiação e promoção, com uma disciplina totalitária de potencialidade despótica, onde podem campear livremente o arbítrio e a coação, de modo mais sutil ou mesmo de forma ostensiva.

Não obstante, se tudo isso é vivido e sofrido pelos atores institucionais, não podemos afirmar que tais atividades e comportamentos sejam deliberadamente planejados e executados por eles. O isolamento no claustro deve ser ainda um "instrumento positivo de reforma" e de transformação do seminarista. Garante principalmente que a autoridade clerical possa ser exercida sobre ele com grande intensidade e um poder incontestável e influente: isolamento individual e individualizante. A coação é assegurada por regras informais que circulam no ambiente institucional. Podemos dizer que há um código não-prescrito, oficioso, circulante e eficiente funcionando no estabelecimento (Barus-Michel, 2004). Todos podem ser vigiados e o medo tem um grande poder condicionador e condicionante.

O tempo do seminarista também fica à disposição dos planos da equipe dirigente: a rotina dos dias no claustro institucional é organizada e outorgada pelos padres formadores ao grupo dos seminaristas, e a partir dela se organiza o "horário da casa". Tempos para as aulas, as orações e missas, estudos e trabalhos domésticos estão ali dispostos. O tempo no seminário é transformado em operador formativo: instrumento de operacionalização da obediência, estar no lugar previsto, na hora certa, fazendo a coisa determinada. Pontualidade e presença se tornam indicadores da "vocacionalidade" do candidato. O seminarista deve usar com "liberdade e responsabilidade" seu tempo livre, dedicando-se aos estudos e a outras atividades formativas. Seu tempo e sua vida devem ser dedicados integralmente à preparação para o sacerdócio.

Apesar do alto nível de vida oferecido pelo seminário, grande parte dos seminaristas, embora vivam como pessoas da classe média, podem ser 
pobres pessoalmente, pois passam os longos anos de formação no claustro do estabelecimento praticamente sem dinheiro para suas necessidades pessoais: roupas, produtos de higiene, livros, fotocópias, viagens para a casa da família, remédios, consultas médicas, oculista, previdência social, plano de saúde, lazer, etc. Há também aqueles cujas famílias têm mais recursos e podem assim ajudar a amealhar uma série de bens de consumo pessoais muito valorizados atualmente: celular, computador, aparelho de televisão, equipamento de som, etc. As "madrinhas de seminário" também podem financiar a aquisição desses bens. $\mathrm{O}$ fato de os seminaristas não pagarem pela formação recebida, ou seja, a gratuidade econômica no processo formativo, tende a produzir ainda outros efeitos interessantes. A irresponsabilidade financeira pode gerar desperdício e depredação: como os seminaristas não pagam, desperdiçar não dói nos seus bolsos, além de torná-los mais exigentes, pois não têm uma noção realista do custo de vida, do preço das coisas. A depredação pode ser entendida também como uma reação às diversas frustrações e pressões que os seminaristas experimentam no estabelecimento. É como se o grupo dos seminaristas pudesse dizer: "Nós demos tudo: alma, vida e coração, corpo e sexualidade, tempo, juventude e liberdade. Temos o direito de receber tudo! O quíntuplo do que demos!" Ao não pagar, o seminarista se sente hóspede, não se vê como sócio, menos ainda como proprietário. Como se responsabilizar por aquilo que não é seu?

Como entender esse aparente paradoxo no funcionamento inadequado de uma formação gratuita numa instituição total? $\mathrm{O}$ aspecto paradoxal pode não ser uma disfunção do sistema, mas a hipótese de que a gratuidade da formação funciona como elemento de controle e de coação dos padres formadores sobre os seminaristas pode torná-la compreensível. Como não paga, o seminarista, que não é sócio nem proprietário, pode ser desligado do estabelecimento sem maiores dificuldades quando a equipe de formadores acreditar necessário. Essa situação de gratuidade, que é a base do poder tutelar dos formadores sobre os seminaristas, ainda produz neles uma condição importante: a postura dependente. Além disso, eles se acostumam a dar tudo e passarão, com o tempo vivido no processo formativo, a perceber como natural o fato de que recebem de volta tudo de graça: privilégio clerical medieval (Cozzens, 2001, p. 102-103). Contudo, o "trabalho doméstico" é considerado como um operador formativo, elemento de transformação do seminarista. Seguindo o modelo monástico, os seminaristas são encarregados de diversos trabalhos: faxina, manutenção, jardinagem, horta, serviços de compras, etc. Como os padres formadores usualmente não "trabalham", nem o clero em geral realiza trabalho braçal, pois conta com empregada doméstica, secretária, ajudantes voluntários, etc., os seminaristas aprendem na prática que trabalho braçal doméstico é para não-clérigos, é para seminaristas leigos. Quando forem padres já não terão que "trabalhar" mais. O trabalho doméstico dos seminaristas pode servir então para mantê-los ocupados dentro do horário minuciosamente organizado do estabelecimento e para a economia com funcionários.

Quanto à dimensão espiritual no seminário teológico, pudemos observar como a referência à "experiência de Deus" não passa mais pelo engajamento político e social, como mostram Libanio (1984) e Pereira (2004). Ela se apresenta de modo mais verticalizado, ligando o indivíduo a Deus; parece mais intimista e subjetiva, transcendendo a problemática social. Podemos afirmar que o modelo monástico oferece a estrutura da espiritualidade proposta, apesar de o padre diocesano ser chamado a uma vocação eminentemente ativa. A vida de oração parece anistórica e intimista, o mesmo se podendo dizer da Eucaristia, que não parece remeter a uma celebração da vida, mas apenas ao culto ritual. Há um destaque para a configuração do seminarista a Jesus Cristo Sacerdote, Profeta e Pastor que nos parece bastante clericalizante, ao identificar com exclusividade o seminarista com os poderes sacerdotais (culto e sacramentos), proféticos (anúncio, pregação da Palavra e ensino) e com o senhorio (pastoreio e governo) de Cristo. Afirmamos que o seminário é clericalizante porque as realidades concretas da vida social praticamente não incidem no processo formativo e os seminaristas são cultivados no seio de uma cultura clerical como uma casta distinta e superior aos demais católicos (Cozzens, 2001, p. 101). Os anos de formação em regime de internato têm como efeito a exclusão do seminarista da participação efetiva na vida civil corrente: formação profissional, emprego, salário e constituição de família, ficando isento das dificuldades cotidianas do cidadão comum. Isso o distancia da vida do povo que deverá liderar mais tarde, alienando-o de aspectos sociopolíticos importantes do mundo contemporâneo. O "desengajamento" e o abandono da militância libertadora é emblemático na expressão de um seminarista teólogo: "Não estudei durante doze anos no seminário para ser sindicalista." Aparentemente, as pessoas sedentas de espiritualidade procurariam no padre hoje, não o profissional intelectual nem o assistente social, mas alguém que é dotado de uma 
profunda espiritualidade pessoal e saiba transmiti-la com sua vida e pregação. Por isso há uma maior preocupação com a vida espiritual e religiosa, mas isolada no ambiente intra-eclesial: o discurso e a prática se voltam para uma experiência pessoal do sagrado, com matizes emocionais, mágicos, que oferecem consolo afetivo e psicológico diante dos desafios da existência (Benelli, 2006b; Benelli \& Costa-Rosa, 2006).

\section{CONCLUSÕES PRELIMINARES}

Embora seja possível que algumas particularidades, como linha teológico-pastoral dominante em dada diocese, o contexto histórico de uma região e o estrato social de onde provêm e a que são destinados os futuros clérigos possam produzir variações nos seminários, por outro lado, essa instituição é regida por regras universais e nacionais e, além disso também há paradigmas eclesiais hegemônicos (Benelli, 2006a; 2006b) cujas influências tendem a superar as coordenadas de espaço e tempo. Por isso estamos interessados nos determinantes estruturais do modo de funcionamento da formação social seminário católico (Costa-Rosa, 2000). A literatura que temos consultado também apresenta notável semellhança e homogeneidade quanto à formação sacerdotal na realidade brasileira e inclusive latino-americana (Marmilicz, 2003; Mézerville, 2000; Pereira, 2004).

Trabalhamos com a hipótese de que o seminário católico, instituição criada pelo Concílio de Trento (Libanio, 1984) para formar o clero, enquadrando e uniformizando a preparação dos candidatos ao sacerdócio, continua sendo, apesar dos diversos adendos "renovados" e "participativos", uma máquina essencialmente clericalizadora. Funcionando a partir das coordenadas do paradigma tridentino, o seminário tende a produzir o que pode: padres clericalizados (Benelli, 2006b). Parece não importar muito que o seminário realmente consiga ensinar Filosofia e Teologia adequadamente para os seminaristas. Se a dimensão acadêmica não logra surtir os efeitos esperados, o mesmo se pode dizer das demais dimensões da formação. Os projetos formativos (Centini \& Manenti, 1988; João Paulo II, 1992; Marmilicz, 2003; Mézerville, 2000; Pereira, 2004) ignoram a realidade histórica do dispositivo institucional subjetivador que costuma constituir o seminário clássico: a técnica do enclaustramento (ingresso do seminarista num espaço institucional fechado de controle, visibilidade e observação de sua conduta externa), a tutela econômica (com a exclusão do seminarista do mundo do trabalho profissional assalariado); o regime de internato (microcosmo particular, de características nitidamente totalitárias (Goffman, 1987) no qual se estabelecem mecanismos de controle sobre a organização dos seminaristas no espaço institucional, além do controle da informação); o panoptismo (Foucault, 1999) que se instala com suas estratégias de vigilância hierárquica, sanção normalizadora e técnicas de exame variadas (mecanismos de controle institucional que produzem medo e resignação). $\mathrm{O}$ seminário parece funcionar mais como uma instituição de gerenciamento do clerical, de cultivo do clerical, do que como formador de "homens de Deus" a serviço dos irmãos (João Paulo II, 1992). Seu aparente fracasso pedagógico manifesta seu êxito em sua função de clericalização dos vocacionados ao sacerdócio. Produzir presbíteros seguidores de Jesus Cristo e continuadores de sua obra seria seu objetivo formal, mas sua dinâmica intra-institucional estaria revelando a produção de padres clericalizados. Mézerville (2000), Cozzens (2001), Marmilicz (2003) e Pereira (2004) constatam os impasses entre discursos altruístas e espirituais e a organização concreta, com suas práticas cotidianas contraditórias. As aporias pedagógicas, psicológicas e disciplinares tornam-se compreensíveis quando situamos o seminário no contexto da sociedade disciplinar (Foucault, 1999) e dos seus paradoxais dispositivos.

\section{REFERÊNCIAS}

Alves-Mazzotti, A. (1999, $2^{\text {a }}$ ed.). O método nas ciências naturais e sociais: pesquisa quantitativa e qualitativa. São Paulo: Pioneira.

Baremblitt, G. F. (Org.) (1998). Compêndio de análise institucional e outras correntes: teoria e prática. Rio de Janeiro: Record: Rosa dos Tempos.

Barus-Michel, J. (2004). O sujeito social. Belo Horizonte: PUC Minas.

Benelli, S. J. (2004). A instituição total como agência de produção de subjetividade na sociedade disciplinar. Estudos de Psicologia, 21(3), 237-252.

Benelli, S. J. (2006a). Pescadores de homens: estudo psicossocial de um seminário católico. São Paulo: UNESP.

Benelli, S. J. (2006b). Paradigmas eclesiais e pedagógicos na formação sacerdotal institucional: uma investigação em Psicologia Social. Revista Eclesiástica Brasileira, 66(264), 807-841.

Benelli, S. J., \& Costa-Rosa, A. (2006). Movimentos religiosos totalitários católicos: efeitos em termos de produção de subjetividade. Estudos de Psicologia, 23(4), 339-358.

Blerger, J. (1980). Temas de psicologia: entrevista e grupos. São Paulo: Martins Fontes. 
Centini, A., \& Manenti, A. (1988). Psicologia e formação: estruturas e dinamismos. (F. R. C. Ferreira \& M. Gastaldi, Trad.). São Paulo: Paulinas.

Conferência Nacional dos Bispos do Brasil. (1995). Formação dos presbiteros da igreja no Brasil: diretrizes básicas. São Paulo: Paulinas.

Costa-Rosa, A. (2000). O modo psicossocial: um paradigma das práticas substitutivas ao modo asilar. Em P. D. C. Amarante (Org.), Ensaios de Loucura \& Civilização. (pp. 141-168). Rio de Janeiro: Fiocruz.

Cozzens, D. B. (2001). A face mutante do sacerdócio: reflexão sobre a crise da alma do sacerdote. São Paulo: Loyola.

Foucault, M. (1999, 21 ${ }^{\text {a }}$ Ed.). Vigiar e punir: nascimento da prisão. (R. Ramalhete, Trad.). Petrópolis: Vozes.

Goffman, E. (1987). Manicômios, prisões e conventos. São Paulo: Perspectiva.

Igreja Católica. (1982). Compêndio do Vaticano II: constituições, decretos, declarações. Petrópolis: Vozes.

Igreja Católica. (1985). Ratio fundamentalis institutionis sacerdotalis. Madrid: Loyola.
João Paulo II (1992). Sobre a formação dos sacerdotes: pastores dabo vobis. São Paulo: Paulinas.

Libanio, J. B. (1984, 2a ed.). A volta à grande disciplina. São Paulo: Loyola.

Lourau, R. (1996). A análise institucional. Petrópolis: Vozes.

Marmilicz, A. (2003). O ambiente educativo nos seminários maiores do Brasil: teoria e prática. Curitiba: Vicentina.

Mézerville, G. (2000). Maturidade Sacerdotal e religiosa: um enfoque integrado entre psicologia e magistério. (J. R Costa, Trad.). São Paulo: Paulus.

Pereira, W. C. C. (2004). A formação religiosa em questão. Petrópolis: Vozes.

Thompson, P. (1992). A voz do passado: a história oral. (L. L. de Oliveira, Trad.). Rio de Janeiro: Paz \& Terra.

Recebido em 15/03/2007

Aceito em 16/08/2007

\section{Endereço para correspondência :}

Sílvio José Benelli, R. José Bonifácio, 1185. Apto. 41 B, Jd. Cristo Rei, CEP: 17513-230, Marília-SP, Brasil.E-mail: sjbewelli@yahoo.com.br 